\title{
A study on peripartum hysterectomy in a tertiary referral government hospital
}

\author{
Chaithra M., Tejeswini K. K.*, Savitha C.
}

Department of Obstetrics and Gynecology, Bangalore Medical College and Research Institute, Bangalore, Karnataka, India

\author{
Received: 23 September 20198 \\ Revised: 14 October 2019 \\ Accepted: 06 November 2019 \\ *Correspondence: \\ Dr. Tejeswini K. K., \\ E-mail: aninaik85@gmail.com
}

Copyright: () the author(s), publisher and licensee Medip Academy. This is an open-access article distributed under the terms of the Creative Commons Attribution Non-Commercial License, which permits unrestricted non-commercial use, distribution, and reproduction in any medium, provided the original work is properly cited.

\section{ABSTRACT}

Background: Emergency peripartum hysterectomy (EPH) is a major surgical venture invariably performed in the setting of life-threatening haemorrhage during or immediately after abdominal and vaginal deliveries. Aim of the study was to study the frequency and indications for peripartum hysterectomy and to assess the maternal outcome of peripartum hysterectomy.

Methods: Cross sectional study was done in the department of obstetrics and gynaecology, Vanivilas hospital, Bangalore from September 2018 to august 2019. This study consists of 24 cases of emergency peripartum hysterectomy within 24 hours of delivery, operated at Vanivilas hospital.

Results: The frequency of peripartum hysterectomy was 1.102/1000 deliveries and following caesarean section and vaginal deliveries are 3.544/1000 deliveries and 0.248/1000 deliveries respectively. Among 24 cases who had peripartum hysterectomy, 16 cases were delivered by caesarean section and 4 cases delivered by vaginal route while another 4 cases delivered by laparotomy for rupture uterus. 22 cases $(91.67 \%)$ survived with major number of cases having morbidities and there were $2(8.33 \%)$ maternal death.

Conclusions: The most common mode of delivery before peripartum hysterectomy was Caesarean section. The most common indication was atonic postpartum haemorrhage. Better protocols for induction and augmentation of labour will decrease the necessity of peripartum hysterectomies.

Keywords: Atonic postpartum hemorrhage, Emergency peripartum hysterectomy, Laparotomy, Placental site bleeding, Traumatic postpartum hemorrhage

\section{INTRODUCTION}

Emergency peripartum hysterectomy (EPH) is a major surgical venture invariably performed in the setting of life-threatening haemorrhage during or immediately after abdominal and vaginal deliveries. ${ }^{1-5}$ It was first proposed in $1869 .{ }^{6}$ Hysterectomy following caesarean section (CS) was first described by Porro and was used to prevent maternal mortality due to post-partum haemorrhage. ${ }^{7}$ In modern obstetrics, the overall incidence of EPH is $0.05 \%$, but there are considerable differences in incidence in different parts of the world, depending on modern obstetric services, standards and awareness of antenatal care, and the effectiveness of family planning activities of a given community. ${ }^{8}$

The risk factors for post-partum haemorrhage include coagulopathies, uterine atony, retained products of conception, precipitate or prolonged labour, foetal macrosomia or multiparity, maternal obesity and previous primary post-partum haemorrhage. ${ }^{9-14}$ Compared with vaginal delivery there is a strong association between 
caesarean section and emergency peripartum hysterectomy. ${ }^{15}$ Because of the increase of both caesarean and artificial reproductive technique induced multiple pregnancy, the incidence of emergency obstetric hysterectomy is likely to raise worldwide. ${ }^{16}$ In the past the most common indications were haemorrhage and rupture uterus. Recent reports show that abnormal placental adherents-placenta previa is emerging as the major indication for obstetric hysterectomy. ${ }^{17}$

\section{METHODS}

This is a cross sectional study for a period of one year from September 2018 to August 2019, of patients who underwent emergency peripartum hysterectomy within 24 hrs of delivery and followed up till discharge from hospital. The sample size was derived by including all the cases of emergency peripartum hysterectomy done during the study period. The study was assessed and analysed by student $\mathrm{t}$ test.

\section{Inclusion criteria}

- All women who underwent emergency peripartum hysterectomy with gestational age more than 28 weeks, within 24 hours following delivery.

\section{Exclusion criteria}

- All women who underwent emergency peripartum hysterectomy with gestational age less than 28 weeks

- Women who underwent obstetric hysterectomy for symptomatic fibroid, cervical dysplasia or carcinoma in situ.

\section{RESULTS}

Table 2 shows out of 24 peripartum hysterectomies, 4 cases $(16.67 \%)$ were following vaginal delivery and 20 cases $(83.33 \%)$ were following caesarean section and laparotomy done for rupture uterus.

Table 1: The frequency of peripartum hysterectomy according to mode of delivery.

\begin{tabular}{|llll|}
\hline Mode of delivery & No. of deliveries & No. of peripartum hysterectomy & Frequency/1000 \\
\hline Vaginal delivery & 16145 & 4 & $0.248 / 1000$ \\
\hline $\begin{array}{l}\text { Caesarean delivery and laparotomy } \\
\text { done for rupture uterus }\end{array}$ & 5642 & 20 & $3.544 / 1000$ \\
\hline Total & $\mathbf{2 1 7 8 7}$ & $\mathbf{2 4}$ & $\mathbf{1 . 1 0 2 / 1 0 0 0}$ \\
\hline
\end{tabular}

Table 2: Distribution of cases based on previous caesarean section.

\begin{tabular}{|ll|l|}
\hline No. of previous c/s & No. of cases & Previous \\
\hline 0 & 11 & $45.83 \%$ \\
\hline 1 & 7 & $29.17 \%$ \\
\hline 2 & 6 & $25 \%$ \\
\hline
\end{tabular}

The frequency of peripartum hysterectomy is $1.102 / 1000$ deliveries and following caesarean section and vaginal deliveries are 3.544/1000 deliveries and 0.248/1000 deliveries respectively.

There were 11 cases $(45.83 \%)$ with no previous $\mathrm{C} / \mathrm{S}$, while 7 cases $(29.17 \%)$, previous $1 \mathrm{c} / \mathrm{s}$ and 6 cases $(25 \%)$ had previous $2 \mathrm{c} / \mathrm{s}$. Table 3 shows among 24 cases who had peripartum hysterectomy, maximum number of cases i.e.., 16 cases were delivered by caesarean section and 4 cases delivered by vaginal route while another 4 cases delivered by laparotomy for rupture uterus.

Table 4 shows that 2 cases were induced with misoprostol and 1 with dinoprostone, while 21 cases were not induced.

Both induction and augmentation were done in 2 cases with no previous CS and 1 case with 1 previous CS. This case with previous CS with preterm IUD was induced with PGE2 and Foley's catheter and augmented with oxytocin ended up with rupture uterus.

Table 3: Distribution of cases in relation to mode of present delivery.

\begin{tabular}{|lll|}
\hline Mode of delivery & No. of cases & Percent \\
\hline Vaginal delivery & 4 & 16.67 \\
\hline Caesarean sections & 16 & 66.66 \\
\hline $\begin{array}{l}\text { Laparotomy for rupture } \\
\text { uterus }\end{array}$ & 4 & 16.67 \\
\hline
\end{tabular}

Table 4: Mode of induction of labour.

\begin{tabular}{|ll|l|}
\hline Mode of induction & $\begin{array}{l}\text { Total no. } \\
\text { of cases }\end{array}$ & Percent \\
\hline No induction & 21 & 87.5 \\
\hline Induction with misoprostol & 2 & 8.33 \\
\hline Induction with dinoprostone & 1 & 4.17 \\
\hline Total & $\mathbf{2 4}$ & $\mathbf{1 0 0}$ \\
\hline
\end{tabular}

Table 6 shows that 16 cases were intra-caesarean hysterectomies, 4 cases were postpartum hysterectomies and 4 cases were hysterectomy following irreparable rupture uterus. 
Table 5: Mode of augmentation of labour.

\begin{tabular}{|lll|}
\hline Mode of augmentation & $\begin{array}{l}\text { Total no. } \\
\text { of cases }\end{array}$ & Percentage \\
\hline No augmentation & 19 & 79.17 \\
\hline Augmentation with oxytocin & 5 & 20.83 \\
\hline Total & $\mathbf{2 4}$ & $\mathbf{1 0 0}$ \\
\hline
\end{tabular}

Table 7 shows that peripartum hysterectomy was done for following indication ie., 12 cases had atonic PPH not responding medical management, 4 cases had irreparable rupture uterus and 8 cases had abnormal placentation with placental site bleed.

Table 6: Distribution of cases according to the time of hysterectomy.

\begin{tabular}{|c|c|c|}
\hline Type of hysterectomy & No. of cases & Percentage \\
\hline Intra-caesarean & 16 & 66.66 \\
\hline Postpartum & 4 & 16.67 \\
\hline Laparotomy (hysterectomy followed by irreparable rupture of uterus) & 4 & 16.67 \\
\hline Total & 24 & 100 \\
\hline
\end{tabular}

Table 7: Distribution of cases showing indications for peripartum hysterectomy.

\begin{tabular}{|lll|}
\hline Indications for peripartum hysterectomy & No. of cases & Percentage \\
\hline Atony & 12 & 50 \\
\hline Rupture uterus & 4 & 16.67 \\
\hline Abnormal placentation & 8 & 33.33 \\
\hline Total & $\mathbf{2 4}$ & $\mathbf{1 0 0}$ \\
\hline
\end{tabular}

Total hysterectomy was performed in 4 cases with abnormal placental site bleeding and subtotal hysterectomy was done in rest of the cases.

\section{Maternal outcome}

In this study group, out of 24 cases, 22 cases (91.67\%) survived with major number of cases having morbidities and there were $2(8.33 \%)$ maternal death.

\section{The morbidities included}

- Prolonged hospital stays: $16(66.66 \%)$

- ICU admission: 7 (29.17\%)

- Disseminated intravascular coagulation: 8 (33.33\%)

- Acute renal failure: 6 (25\%) of which $2(8.33 \%)$ required dialysis

- Electrolyte imbalance: 4 (16.67\%)

- Pulmonary oedema: $2(8.33 \%)$.

- Wound infection:2 $(8.33 \%)$

- Wound gaping: $1(4.17 \%)$

- Massive blood transfusion: 4 (16.67\%).

\section{Mortality cases}

There were 2 maternal death.

- Case 1: PPH with DIC (antecedent cause- severe anaemia with abruption placenta with uterine atony)

- Case2: PPH with hypovolemic shock (antecedent cause- placenta previa with APH).

\section{DISCUSSION}

Frequency of peripartum hysterectomy in our study was $1.102 / 1000$ deliveries, whereas in Joana Ferreira Carvalho JF et al study was 0.41 per 1,000 deliveries and in Sharma B, et al study was $6.9 / 1000$ deliveries. ${ }^{18,19}$

In present study 4 peripartum hysterectomy (16.67\%) were following vaginal delivery and 20 cases $(83.33 \%)$ were following caesarean section and laparotomy done for rupture uterus whereas in Carvalho JF, et al study the majority of cases who underwent peripartum hysterectomy (8/13) were following caesarean delivery. ${ }^{18}$ In present study, $33.33 \%$ had DIC, $8.33 \%$ had wound infection, and there were 2 maternal deaths.

In Sharma B et al, study disseminated intravascular coagulation was seen in $12.5 \%$, and wound infection was seen in $5 \%$ of the women. There were $4(10 \%)$ maternal deaths. Cause of maternal death in all was atonic PPH.

\section{CONCLUSION}

Peripartum hysterectomy represents a catastrophic end to a pregnancy for any woman, regardless of whether she considers her family to be complete or not.

Identification of the high-risk factors antenatally and delivery of such cases in an institution or referral centres by skilled birth attendants and following protocols of action, measures that can contribute to reduce high 
maternal morbidity and mortality associated with emergency peripartum hysterectomy.

Funding: No funding sources

Conflict of interest: None declared

Ethical approval: The study was approved by the Institutional Ethics Committee

\section{REFERENCES}

1. Christopoulos P, Hassiakos D, Tsitoura A, Panoulis K, Papadias K, Vitoratos N. Obstetric hysterectomy.A review of cases over 16 years. J Obstet Gynecol. 2011;31(2):139-41.

2. Kwee A, Boto ML, Visser GH, Bruinse HW. Emergency peripartum hysterectomy: a prospective study in The Netherlands. Eur J Obstet Gynecol Reprod Biol. 2006;124(2):187-92.

3. Karayalcin K, Ozcan S, Ozyer S, Mollamahmutoglu L, Danisman N. Emergency peripartum hysterectomy. Arch Gynecol Obstet. 2010;283(4):723-7.

4. El Jallad MF, Zayed F, Al-Rimawi HS. Emergency peripartum hysterectomy in Northern Jordon: indications and obstetric outcome (an 8-year review). Arch Gynecol Obstet. 2004;270(4):271-3.

5. Zamzami TY. Indications of emergency peripartum hysterectomy: review of 17 cases. Arch Gynecol Obstet. 2003;268(3):131-5.

6. Daskalakis GE, Anastasakis N, Papantoniou S, Mesogitis M, Theodora, Antsaklis A. Emergency obstetric hysterectomy. Acta Obstetricia Gynecologica Scandinavica. 2007;86(2):223-7.

7. Parro E. Dell amputazione utero-ovarica come complement di taglio cescareo. Ann leniv Med chir. Clin Obstet Gynecol. 1969;12(3):575-89.

8. Park EH, Sachs BP. Postpartum haemorrhage and other problems of third stage, in high risk pregnancy management options. 2nd edition. W.B. Saunders, Philadelphia, USA. 1999:1231-46.

9. Engelsen IB, Albrechtsen S, Iversen OE. Peripartum hysterectomy incidence and maternal morbidity. Acta Obstet Gynecol Scand. 2001;80(5):409-12.
10. Langdana M, Geary W, Haw D, Keane F. Peripartum hysterectomy in the 1990s: any new lessons? J Obstet Gynecol. 2001;21:121-3.

11. Sheiner E, Levy A, Katz M, Mazor M. Identifying risk factor for peripartum cesarean hysterectomy. A population based study. J Reprod Med. 2003;48(8):622-6.

12. Kastner ES, Figueroa R, Garry D, Maulik D. Emergency peripartum: experience at a community teaching hospital. Obstet Gynecol. 2002;99:971-5.

13. Bakshi S, Meyer BA. Indications for and outcome of emergency peripartum hysterectomy. A five year review. J Reprod Med. 2000;45(9):733-7.

14. Zelop CM, Harlow BL, Frigoletto FD, Safon LE, Saltzman DH. Emergency peripartum hysterectomy. Am J Obstet Gynecol. 1993;168:1443-8.

15. Stanco LM, Schrimmer DB, Paul RH, Mishell DR. Emergency peripartum hysterectomy and associated risk factors. Am J Obstet Gynecol. 1993;168(3):87983.

16. Kerr JM, Baskett TF, Calder AA. Kumaran SA. Operative obstetric. $11^{\text {th }}$ edition.2007:175-180.

17. Mousa HA, Alfirevic Z. Treatment for PPH. Cochrane Database Syst Rev. 2007;(1):CD003249.

18. Carvalho JF, Cubal A, Torres S, Costa F, Carmo CO. Emergency peripartum hysterectomy: a 10-year review. ISRN Emergency Medicine. 2012;72:191-8.

19. Sharma B, Sikka P, Jain V, Jain K, Bagga R, Suri V. Peripartum hysterectomy in a tertiary care hospital: Epidemiology and outcomes. JOACP. 2017;33(3):324-8.

Cite this article as: Chaithra M, Tejeswini KK, Savitha C. A study on peripartum hysterectomy in a tertiary referral government hospital. Int J Reprod Contracept Obstet Gynecol 2019;8:4971-4. 